\title{
Significant Structuring Resources in the Reading Practices of a Digital Classroom
}

\section{Lisa Molin \\ Department of Applied IT, University of Gothenburg, Sweden}

\author{
Annika Lantz-Andersson \\ Department of Education, \\ Communication and Learning, \\ University of Gothenburg,. \\ Sweden
}

annika.lantz-andersson@ped.gu.se

\section{Abstract}

Since reading and writing digitally demand partially different competencies, there is a change in some of the premises of related educational practices. This study aims to contribute to the knowledge of educational reading practices by scrutinizing how literacy events evolve in a digital classroom where each student has a personal digital device (1:1), iPads in this study. Our study is grounded in sociocultural theories of learning and focuses on the structuring resources utilized by students, namely the notion of multiple ongoing activities and the ways in which specific resources take precedence in shaping these activities. One class of 13-14 year-old students was studied for a week across several subjects through video-recordings and observations. The findings imply that the students moved among vast array of reading practices. However, the main structuring resource is a strong focus on task-solving and the practice of schooling, which mainly builds on principles emanating from traditional text. It is only occasionally that structuring resources that also include the opportunities associated with digital technology are utilized. This indicates the importance of further studies on how educational practices could be organized to scaffold the basis of traditional reading comprehension as well as other approaches required in digital environments.

Keywords: literacy, digital technologies, interaction analysis, reading practices, structural resources

\section{Introduction}

Digital technologies are becoming increasingly common in schools in the western world, and Sweden is no exception. A majority of Swedish municipalities today run 1:1 projects, where schools provide one personal device per

Material published as part of this publication, either on-line or in print, is copyrighted by the Informing Science Institute. Permission to make digital or paper copy of part or all of these works for personal or classroom use is granted without fee provided that the copies are not made or distributed for profit or commercial advantage AND that copies 1) bear this notice in full and 2) give the full citation on the first page. It is permissible to abstract these works so long as credit is given. To copy in all other cases or to republish or to post on a server or to redistribute to lists requires specific permission and payment of a fee. Contact Publisher@InformingScience.org to request redistribution permission. student. Implementations are in some cases preceded with some professional development but they rarely include surveys of teachers' or students' prior digital literacy skills. In some cases mappings of such kind are rather performed in a later phase post implementation, e.g., in the evaluation processes (Andersson, Hatakka, Grönlund, \& Wiklund, 2014). 
Access to digital devices for all students all the time changes the basic premises for educational practices and implies challenges for schools, teachers, and students. This reflects societal development in general in relation to how digital and mobile technologies change the ways we communicate, learn, and act in everyday settings. These media ecologies have emerged over a few decades (Levinson, 1999; McLuhan \& Lapham, 1994), and it is essential to examine the implications for learning as well as the basic expectations regarding what it means to learn and know (Säljö, 2010).

For centuries, traditional typographical text and reading has been a central resource for teaching and learning within education. In general, text used to be the only representation for accumulated knowledge. However, the rapid and extensive development of digital technologies has changed the premises of the use of texts in the classroom, since the manner in which text is represented varies greatly. This has lead to increasing policy discussion and research attention related to literacies and what it means to be literate in modern society. The term literacy traditionally referred to the ability to read, write, and use printed text in different contexts (Kress, 2003). However, digital technologies offer possibilities for other modes of communication apart from printed text, e.g., still and moving images and audio. This implies that digital reading and writing demands partially different competences, strategies, and knowledge, which is reflected in the concept of 'new literacies' (Leu, Kinzer, Coiro, \& Cammack, 2004). Thus, it is interesting to examine how reading activities evolve in 1:1 classrooms related to the use of digital technologies and teachers' instructions in order to rethink familiar perspectives on classroom learning and prepare students for their future in literacy (cf. Andersson et al., 2014).

\section{Aim and Research Questions}

This study explores literacy events where digital technologies are used by both students and teachers. By grounding the study in sociocultural theories of learning, the aim of this study is to scrutinize the in situ reading practices in a 1:1 educational context in relation to digital technologies and instruction (Säljö, 2010; Wells, 1999; Wertsch, 1998). The analysis further focuses on the structuring resources utilized by the students, meaning the notion of multiple ongoing activities and the ways in which specific resources become superordinate and take precedence in shaping educational activities (Lave, 1988). This entails studying what can be considered structuring resources in the students' work and what this implies for evoking reading practices.

When societies and institutions develop and change, the cultural and social conditions for people's literacy practices also change. Therefore, this study draws upon the notion of 'reading' as a social practice, referring to different social procedures that are constructed interactively by students and teachers in classrooms (Baker, 2010; Street, 1984). The focus of the study is to describe and explore the reading practices that take place in the classroom and how technologies, peers, and instruction supports and scaffolds these practices by functioning as structural resources.

The analysis of the reading practices draws on the Four Resources Model (Freebody \& Luke, $1990,1999,2003)$. The model encapsulates the implications of being literate today, with particular attention to reading, and recognizes four multi-literate requirements for reading effectively in a multimodal world - break the code of texts, participate in the meaning of texts, use text functionally, and critically analyse and transform text. The model is based on literacy events as socially constructed and situated in specific contexts, which parallels the basis of this study.

The study is part of a larger project where one class was followed over one school year. The project includes videodocumentation, participant observations, and interviews. In the present case study, the specific focus is on the different reading practices present within five theoretical subjects during one school week. In addition, the teacher instructions, such as scaffolding and other 
supporting structures, are analysed in order to scrutinize how the practices and instructions are related.

The following research questions have guided our research:

- What reading practices are significant in a 1:1 educational context?

- Which aspects become structuring resources in the students' activities during a regular school week and what does this imply in terms of evoking reading practices?

\section{Previous Research}

\section{Transition from an analogue to a digital learning environment.}

As argued in the introduction, the use of digital technologies implies changed conditions for reading as a resource for learning within education. The employments of digital technologies in classrooms are recurrently referred to in favourable terms, but there are also more sceptical views on how much technologies actually change practices. The more promising voices indicate results of increasing motivation (e.g., Papastergion, 2009; Uschioda, 2011; Yang \& Wu, 2012), more personalized learning, and variations in teaching methods (e.g., Buckingham, 2013; Collins \& Halverson, 2009; Kalantzis, Cope, \& Harvey, 2010). While researchers that formulate a more sceptical view argue that above all it is important to realize that due to the complex practice of schooling, the use of technologies does not automatically imply development in a more fundamental sense (Andersson et. al., 2014; Fleischer, 2012; Goodwin, 2011; Selwyn, 2015; Tallvid, Lundin, Svensson, \& Lindström, 2015).

Since Cuban's (2001) early findings of the use of digital technologies in school, implementing technologies in school practice has proven to be a slow process; moreover, it is difficult to predict in what manner adaptation is done or what results the implementation will yield (Orlikowski, 2007). However, there exist certain common patterns irrespective of the implemented technologies. Such patterns indicate an initial phase with doubts regarding costs and value, which is followed by a gradual acceptance and integration of the technologies in everyday schooling. Obvious examples of this is how the use of calculators, watching videos, or posting assignments digitally instead of handwritten on paper caused huge debates and skepticism at the time of implementation, but are now accepted (Oldknow \& Taylor, 2003; Tallvid et al., 2015). Implementation of new technologies may also imply that they are used in a similar manner as the old ones, for example, reading a PDF from an iPad instead of a piece of paper. This is initially common in digital environments and could be considered a first or initial step in the development process. Within this transition from an analogue to a digital classroom, it is necessary to draw attention to questions regarding a more deliberate use of technologies, which include complex issues surrounding teaching and learning (cf. Inan \& Lowther, 2010; Säljö, 2010; Tallvid et al., 2015).

Explanations of why the transitions from analogue to digital classrooms often become slow and rather uncontrollable are highlighted in several research findings. Lack of equipment and technical support are two main issues. Moreover, teachers' attitudes are also indicated to be crucial for if and how they integrate digital technologies in the classroom or limit their use to administration and lesson planning (Andersson et al., 2014; Ertmer, Ottenbreit-Leftwich, Sadik, Sendurur, \& Sendurur, 2012; European Commission, 2011; Fleischer, 2012; Goodwin, 2011; Jones, 2014; Sipilä, 2011). Furthermore, since the 1:1 environment often entails more student-centred classroom practices, the position of the teacher changes radically; this also implies a change in expectations of teacher knowledge. Implementing new technologies entail expectations not only on the teachers' pedagogical and content knowledge but also demands technical knowledge, which may cause reluctance (Cuban, 2013; Donovan, Hartley, \& Strudler, 2007). Therefore, preconceptions of teaching and learning and the role of the teacher are crucial in examining and discussing evolv- 
ing practices. For students, this transition also implies changed conditions. Findings from earlier studies show that students express benefits in terms of effectiveness in communication and seeking information; however, it is also indicated that they need support in activities such as searching, reading, and reflecting on information (Coiro, 2011; Fleischer, 2012; Oliver \& Corn, 2008), which confirms the need for more knowledge of teachers' scaffolding and the use of different artefacts in a digital classroom.

\section{Changes in literacy practices in education}

Since literacy has been regarded as crucial for learning for centuries, education has played an important role in supporting the development of literacy skills in line with the societal needs of the time (Säljö, 2012). The traditional concept of literacy, which earlier mainly implied decoding and memorizing texts, has been transformed into a basis for comprehension, which is in line with the last century of extensive increase in texts and rapid technology developments (Wegerif, Mercer, \& Dawes, 1999). Due to the development of digital technologies, text is currently represented in an indefinite number of variations, where the traditional text is still present but accompanied, and occasionally replaced, by multimodal elements (see, e.g., Öman \& Sofkova Hashemi, 2015; Rasmusson \& Eklund, 2013; Serafini, 2012).

Consequently, the traditional concept of literacy is questioned and considered too narrow by many scholars (e.g., Kress, 2003; Leu, Kinzer, Coiro, Castek, \& Henry, 2013). This has resulted in a development where some scholars argue that literacies must be related to in a pluralistic sense (e.g., Østerud, 2004), while others maintain that new terms should be added-for example, media literacy, visual literacy, information literacy, digital literacy, etc. (e.g., Buckingham, 2003, Erstad, 2006, Shapiro \& Hughes, 1996). Today, the concept of literacy is also often even used as a synonym for expressions such as knowledge, competence, and learning. The changing concept of literacy originated in the New Literacy Studies (NLS) in the 1970s and 1980s; this concept expanded the notion of literacy beyond the more traditional form to also take into account sociocultural influences (Gee, 1991; Scribner \& Cole, 1981; Street, 1984). In NLS, literacy is understood as being situated in different activities, cultures, social contexts, and media. This entails that the social practice of literacy skills becomes the focus, rather than merely conventional reading and writing skills. Even though digital technologies offer new possibilities to accomplish tasks, the premises for this study also presuppose that the social practices of schooling have emerged through history, and these practices include certain procedures and habits with many, both explicit and implicit rules, that are not straightforwardly changed (Edwards \& Mercer, 1987; Selwyn, 1999).

The development of digital technologies has gradually widened our perception of text. The representation of text is fundamentally different from only a few decades ago. Contemporary texts contain meaning through typographical symbols, which are supposed to be read both linearly and through multimodal, non-linear, hyper-text representations (Kress, 2003). Today, multimodal texts surround us via different types of media and play important roles in communication and learning, thereby transforming what reading is about. Main organisations, such as the Organisation for Economic and Co-operation and Development (OECD), The European Commission, and national policy documents of European countries and the United States pay attention to this change and its implications for reading, elaborating new definitions for reading literacy. For example, OECD conducts the large-scale international PISA-studies, where reading skills among 15 -year-olds is tested every third year. OECD use the concept of reading literacy which is defined as "using, reflecting on and engaging with written texts, in order to achieve one's goals, to develop one's knowledge and potential, and to participate in society" (OECD, 2015, p. 9). The phrase "written text" is stated as comprising all texts in graphic forms including handwritten, printed, and on-screen texts. This also includes dynamic texts like hyperlinks where readers need 
to construct their own pathways to complete the reading activities as well as visual modes such as diagrams, pictures, maps, tables, graphs, and comic strips (OECD, 2015, p. 9). This study has a particular focus on reading practices in a digital classroom environment. The concept of reading literacy is therefore used as a point of departure in order to capture the extensive notion of what it is to read today. Such a perception of the concept of literacy implies that describing reading literacy practices in education today is complex. For example, extensive online reading on mobile digital technologies as a resource for learning has been a subject for debate, particularly with regard to reading comprehension. Skeptics claim, among other things, that online reading is more cognitively demanding compared to reading from paper, as it entails more fragmented literacy practices (e.g., Mangen, Walgermo, \& Brönnick, 2013). On the other hand, advocates argue that reading comprehension is not so different either done on the screen or on paper. Moreover, the varieties and access to an indefinite amount of information will contribute to more learning possibilities than ever before, and searching, selecting, evaluating, and critically scrutinizing information are all claimed to be important and necessary skills today (Ackerman \& Goldsmith, 2011; Baker, 2010; Kim \& Huynh, 2010).

However, as a way of contributing to the teaching of reading, many researchers have paid attention to the general skills that are required for comprehension, both traditional reading skills and online reading skills. Reading comprehension is a complex activity involving multiple components, such as reading speed, verbal memory, ability to pay and keep attention, word knowledge, and engagement (e.g., Guthrie, Klauda, \& Ho, 2013). Furthermore, previous knowledge of content is identified as an important factor that co-determines enhanced learning (Coiro, 2011; Dole, Duffy, Roehler, \& Pearson, 1991; Pearson \& Gallagher, 1983). It has also been indicated that comprehension strategies facilitate the reader to adapt to different types of texts and tasks. Such strategies for reading comprehension may be to determine relevance, summarize, draw conclusions, and verify one's own comprehension (Dole et al., 1991). Consequently, comprehension strategies are crucial irrespective of whether the reading occurs on paper or in a digital environment (Chan \& Unsworth, 2011; Dalton \& Smith, 2012; Rasmusson \& Eklund, 2013). However, certain reading skills are identified to be partly different for online reading and, consequently, for comprehension. Online reading involves not only traditional reading skills of linear, typographical texts but also includes multimodal literacy for interpreting signs and symbols and identifing hyperlinks, strategies for finding the right path in information searching, and interpreting structures and adopting a critical stance towards the text. Other crucial skills necessary for online reading are to be able to handle the technology and understand the structure of the web (Kress, 2003; Rasmusson \& Eklund, 2013). A focus and an awareness on both traditional and online reading skills becomes central for how activities of reading and writing are understood in relation to digital technology in the context of schooling.

Several studies pay attention to teachers' use of multimodal resources within the context of teaching reading. Dalton and Smith (2012) studied the teaching strategies for digital reading by utilizing a web-based tool in several subjects. The lessons studied contained several modalities such as script, video, simulation games, animations, sound, and pictures. They found that teachers focus on scaffolding the students' reading comprehension strategies by using specific features of the tool as well as teaching strategies and media literacy, to a minor extent. However, students' practise of multimodal skills such as creating photo stories, cartoons, and podcasts within the frame of the planned lessons was left without teacher support.

Earlier studies have also paid attention to the online reading comprehension of students with poor traditional reading skills. For example, Chan and Unsworth (2011) found that the online environment provides support for the students, since digital texts offer other modalities included in the texts. Pictures were found to facilitate comprehension if they were coherent with the script, but if the text and picture were complementary and contained information that the students had to 
collect and synthesize, it became more demanding for them to form a meaningful coherence. The authors concluded that teachers' scaffolding was necessary since the students encountered challenges in navigation and creating consistency between typographical linear text, non-linear text, and visual and verbal information.

In a recent study by Öman and Svensson (2015), primary students' interaction in group-work activities and how they utilized the features of the laptops was explored. The findings imply that in some of the groups the digital technology played a rather passive role during the collaboration, while in other groups the tool became more of an interactive partner which opened up new learning possibilities. However, it is not the digital technology per se that scaffolds the interaction, but rather the opening up of possibilities for learning depending on how the students handle the technology, which in turn is often connected to teachers' instructions. Thus, their findings indicated that to enhance interactive collaborative work with technology, teachers' instructions, scaffolding, and careful design of the task is of outmost importance.

Taken together, earlier research shows that the amount and variety of text that are provided through digital technologies have implications for learning activities in schools. Therefore, an important challenge for educational institutions and teachers today is to find ways to support the students in developing literacy skills in a broader sense than before. Traditional reading skills as well as online reading skills need attention in order to provide the students with the skills they need for comprehension of text and, consequently, for their learning in school. Thus, studying in situ school literacy practices when students are using digital technologies will provide us with important knowledge regarding how text is represented and used naturally in such contexts, thereby also enabling an elaboration on how teachers' instructions may scaffold students' reading literacy.

\section{Theoretical Framework}

Analytically, the study draws on sociocultural perspectives where learning is regarded as situated within activity, context, and culture through the interaction between participants and tools used (Lave, 1988; Vygotsky 1939/1978; Wells, 1999; Wertsch, 1998). Sociocultural studies focus on interactional and negotiable aspects of adopting various cultural tools and language is considered the most important tool. Everything that interplays with what occurs in activities could be referred to as structuring resources (Lave, 1988; Lave \& Wenger, 1991), in other words resources that shape the activity that participants utilize as well as other conditions that limit what is possible in an activity. The context is considered an integral part of human action and an important aspect in providing structuring resources for how to handle tasks. The experiences of people in activities they are involved in function as structuring resources in other situations. The more familiar an individual is with structuring resources in a particular practice, such as the school, the easier it is to act on these resources. Thus, structuring resources are everything that participants in an activity evoke to make sense, for example, knowledge of the specific setting, previous experiences, assumptions, expectations, the way the technologies are utilized, and interaction with other participants (cf. Rasmusson \& Eklund, 2013; Skantz Åberg, Lantz-Andersson, \& Pramling, 2015). In Vygoskian terminology, teachers' support, or scaffolding, is the main structuring resource as part of schooling; however, scaffolding could also be provided by more capable peers. Scaffolding is understood as a kind of support that initially helps the learner to achieve goals beyond his or her capacity, thereby aiming at developing a more independent competence (Vygotsky, 1939/1978). In this study, the theoretical underpinning implies that we explore in situ practices by emphasising which structuring resources, including the teachers' and other students' scaffolding, the students take advantage of by focusing on multiple ongoing actions and how this shapes evolving reading practices. 


\section{Method}

This study is part of a larger research project that was performed in a Swedish suburban school during the school year 2012-2013, in a class of 13-14 year-olds who participated in a one-year iPad-venture. However, the iPad technology as such is not central in this study but rather the 1:1 technology setting is the focus. The venture continued for a year before evaluating the outcome and deciding whether to extend the 1:1 solution to involve all classes from year 1 to year 9 in the school. Overall, the research project included participant observations, video recordings, and interviews. The case study presented here was conducted during one school week during the spring semester of 2013, and includes observations and video recordings. However, even though interviews were not explicitly a part of this study they have indirectly informed the researchers' interpretation of the observations and video recordings.

The case study approach was chosen to establish an in-depth understanding of an ongoing everyday practice in a setting where digital technology was already used as part of an ordinary school day (Yin, 2012). The study was conducted during lessons in mandatory subjects - Chemistry, History, Swedish, English as a foreign language, and Mathematics in a secondary school class that worked with iPads as personal devices $(1: 1)$. The focus of the study is, thus, to scrutinize the in situ practices that occur regardless of the students' prior digital literacy skills. No surveys or investigation was done regarding the teachers' or student' previous digital habits and skills, when the project of implementing personal digital devices was conducted, which is comparable with how many 1: 1 projects in Sweden have been carried out (cf. Andersson et al., 2014).

The focus of this particular study is reading literacy embodied within a school context through reading practices. Support for describing reading as an activity that encourages participation in and co-creation of reading practices can, from an analytical perspective, be found in ethnography (Hymes, 1967, 1972). A reading practice is considered situated in a specific context, which concerns both the physical context as well as the psychological and cultural frames, such as the cultural interpretation and comprehension of the reading material. Who is participating and the purpose of the reading is also crucial. By growing up within a specific culture, within which different reading practices may develop, an individual is provided opportunities to participate in and cocreate reading practices within this culture. For example, today, even very small children participate in a reading culture by becoming acquainted with text through picture books or iPads, without yet being able to decode traditional text (Davidson, Kline, \& Snow, 1986; Findahl, 2012, p. 18).

Consequently, in order to regard literacy as a social phenomenon (e.g. Scribner \& Cole, 1981; Street, 1998), studies on reading practices need to be conducted in situ. This study draws on ethnography, particularly participant observation and videorecordings that also include nonverbal resources in interaction. This implies that the lessons were videorecorded and observed.

The recordings and observations were taken in whole-class activities, groupwork, and individual work. The video recordings were mainly made in Swedish, English, and Chemistry subjects, and made with one camera to capture an overview angle with temporary shift of focus on smaller groups and individuals. Individual screens were also zoomed in temporarily to capture specific examples that could enhance the analysis of the particular activity that was taking place. The teachers were videorecorded in whole-class instruction or one-to-one instruction. The class activities in Mathematics and History were mainly documented through observations and notetaking, but the empirical findings from some of the lessons mentioned below are based on a combination of transcribed videorecordings and fieldnotes from observations as well as analysis of the transcribed interviews (see Table 1). 
Table 1: The data of the study

\begin{tabular}{|l|l|l|}
\hline Subjects & Method of data collection & Type of data \\
\hline Chemistry & Videorecordings, observations & $\begin{array}{l}\text { Instructions given by the teacher } \\
\text { Whole-class activity } \\
\text { Group work-answering questions } \\
\text { Group work-to do laboratory work and write a } \\
\text { lab report }\end{array}$ \\
\hline History & Observations, & $\begin{array}{l}\text { Instructions given by the teacher } \\
\text { Whole-class activity } \\
\text { Individual task-answering questions }\end{array}$ \\
\hline Swedish & Videorecordings, observations & $\begin{array}{l}\text { Instructions given by the teacher } \\
\text { Whole-class activity } \\
\text { Individual writing task }\end{array}$ \\
\hline English & Videorecordings, observations & $\begin{array}{l}\text { Instructions given by the teacher } \\
\text { Whole class activity } \\
\text { Individual task-answering questions }\end{array}$ \\
\hline Mathematics & Observations & Pair work-answering questions \\
\hline
\end{tabular}

\section{Analysing and Presenting the Empirical Material}

The analysis of the videorecording and the fieldnotes drew on Interaction Analysis (Jordan \& Henderson, 1995) to examine how the participants utilized various resources in the complex social and material context in which they act. With its roots in ethnography (particularly participant observation), sociolinguistics, ethnomethodology, conversation analysis, and other traditions that also include nonverbal resources in interaction, Interaction Analysis enables the study of knowledge and action as socially constituted. When studying interaction in classrooms, the focus is both on what students and teachers say and how they act with different tools. One important assumption in Interaction Analysis that corresponds to the sociocultural tradition is that knowledge is not considered something localized in each individual's head but as situated in the interaction between participants in activities.

The first step of analysing the data was to view the observation notes and videomaterial and create a broad transcript. Then, longer chunks of interaction were reviewed and transcribed and, thereafter, certain cases were selected from the entire material for further analysis of the interaction. These cases were chosen since they illustrated diverse reading practices that to a varying extent involved the digital tool, not only in different lessons but also within the same lesson. A careful analysis of the empirical material was then done to confirm or contradict the first preliminary findings. Thereafter, the reading practices were identified by using the Four Resources Model (Freebody \& Luke, 1990, 1999, 2003, this model is also used more recently in, e.g., Serafini, 2012). The model recognizes what it is to be literate today, encourages that reading and writing are always situated in specific contexts with specific purposes, and also acknowledges that text goes beyond print and paper. Thus, the model becomes a useful tool in analysing reading practices in a classroom comprising both traditional and multimodal literacies and how teacher instructions co-determine the literacy event taking place. Freebody and Luke (1990, 1999, 2003) argue that "it is through social interaction around literacy events that we learn our position as reader and our notion of what for us the texts are for" (p. 11). The model embraces the following four practices that are intertwined and of equal importance, as readers often engage in several practices together: a) break the code of texts, b) participate in the meanings of text, c) use text functionally, and d) critically analyse and transform text. To break the code of texts is to recog- 
nize and use features such as alphabet, sounds, spelling, conventions, and the patterns of the text. To participate in the meanings of text includes understanding and composing meaningful written, visual, and spoken texts from within particular cultures, institutions, communities, and so on. To use texts functionally is further defined as knowing about and acting on the different cultural and social functions that various texts perform both within and outside of school. To understand how these functions shape the ways texts are constructed, their tone and degree of formality as well as their sequence of components become important. However, it could be considered, rather pragmatically, to recognize "what is this text for, here and now" (Freebody \& Luke, 1990, p.10). Finally, to critically analyse and transform texts concerns understanding and acting on the knowledge that texts are not natural or neutral but represent particular views, silence others, and influence people's ideas. Text designs and discourses can also be critiqued and redesigned in novel and hybrid ways, which becomes easily accessible in a digital environment in particular.

The analysis proceeded by focusing on what the students were oriented to and what the structuring resources were during the course of different classes, if they used digital technologies, andif they did-in what ways and how they supported the reading practices taking place. Thus, the analysis varied between studying the broader ethnographic descriptions and analysing the transcribed sequences from the video documentation of the students' interactions. This process included discussions on particular transcribed parts and watching the same sequence numerous times to be able to understand how the students and the teachers performed in the in situ moments and, by that, being able to make analytical comments on their understanding of the practice. By also scrutinizing and comparing different sequences we could subsequently make analytical claims about the way a particular case could be said to involve examples of the four literacy practices. In order to describe the classroom activities and student interactions with each other and with the teachers, we chose to present the material partially as an ethnographic narrative and partially with specifically selected transcribed excerpts, mostly from the videorecordings but also some from the interviews. Choosing several mandatory theoretical subjects provides an opportunity to reveal as wide a diversity as possible across and within different lessons and subjects throughout a school week. This enables us to take into consideration and explore how students interact across multiple forms of literate activities (cf., Prior \& Thorne, 2014).

The majority of the excerpts are originally in Swedish and have been translated into English by taking into consideration the essence of what the students said. In most cases, the translations have been done word-by-word and with respect to the specific activity, there has been an effort to use translated words that appeared suitable for the context at hand (Duranti, 1997). This implies that the Swedish expressions used by the students have been translated into colloquial informal English expressions to take into account that the empirical material comprises communication between 13 to14-year-old students. In the transcribed excerpts the annotation (.) is adapted for a brief pause and ((italic text)) for nonverbal activity deriving from Jeffersons' conventions (1984).

\section{Ethical Considerations}

In line with the Swedish Research Council's ethical guidelines for research (Codex, 2010), the students were informed about the research and all signed a consent form to participate in the study and to being videorecorded in the classroom. Since all the students were under 18 years old, their parents also signed a consent form. The students were informed that they could discontinue their participation in the study anytime during data collection, and the students who declined being filmed have not been documented at all. Consequently, the students who were recorded and whose excerpts were used actively provided their consent to participate in the study. The names used for the students are all fictitious and when videofilms or photos were used in research contexts, the participants were portrayed as anonymous. 


\section{The Context of Data Collection}

As mentioned earlier, the class was running a pilot iPad project and all students had access to their devices at all time and used them in all theoretical subjects during the school day. Practicalaesthetic subjects only used the technology temporarily and, therefore, are not part of this study. The assignments in the different subjects were given by the subject teachers with no interventions from the researchers. The classroom organisation of the work varied between lessons and within lessons. Some of the work was performed through whole-class activities and some through smallgroup activities as well as individual work. Three teachers were involved. One was a History teacher, one was a Swedish and English teacher, and the third was a Chemistry and Mathematics teacher.

\section{Empirical Findings}

In the following section, activities in the five lessons will be presented. Examples and excerpts serve to illustrate how the teachers and students are involved in a variety of reading practices that they move between during the week in which the case study was conducted and how different structural resources are invoked in the students' activities.

\section{Chemistry}

The content of this Chemistry lesson of 120 minutes is to rehearse the periodic table, to do a laboratory study on the $\mathrm{pH}$-value of liquids, and finally to write a lab report. The students had prepared for the lesson by reading questions and instructions regarding the periodic table from a closed Facebook group (FB) that the class has created. Previous lessons also involved readings and instructions related to the periodic table. Once in the classroom, the class is organized in small groups. As a way of further deepening the comprehension of the content and reading, they are instructed to answer the FB questions regarding the periodic table and to document the answers on their iPads. Their results were to be presented to the entire class in a subsequent lesson.

The excerpt below is from a discussion in a group comprising four students on how to organize the notetaking and distribution of answers.

Excerpt 1, Group A

1. Anton We must organize (.) how this discussion has to be conducted. It must be fair (.) so everyone is part of it. We could take one question at a time and let each and everyone answer, one at a time, before going on to the next question (.) As a structure. And we'll get good and complete answers, I think.

2. Sofia How should we take notes then?

((The group is quiet for a little while))

3. Anton We could use one iPad which is sent around (.). You know, open a new Pages document, write there, and then e-mail it to all of us and to Anne (teacher)

((After this statement they begin the activity))

In order for the group discussion to serve as an effective structuring resource for the students' comprehension of and performance in the task, the structure of the talk initially appears crucial and some negotiations are done to reach consensus. What is also central is to define how the technology can be used in the most suitable manner. Instead of using the features of the iPad, like sharing documents online (e.g., Dropbox or Google Drive), the students depend on their previous experiences and send the iPad around the group as if it were an ordinary notebook. Hence, the technology mostly becomes an add-on to a previous practice, with the only change being that it facilitates the handling and distribution of the document. 
The teacher's intention for the group activity is to support comprehension of the periodic table, which is the subject-specific text here. The group activity could be a scaffolding resource supporting students' comprehension; however, the students merely focus on how to perform the school task. Therefore, by picking up the generic expectations of what it implies to answer questions in a classroom context as functionally, democratically, and smoothly as possible, they act as text users and mainly use the text functionally (cf. Freebody \& Luke, 1990).

Transforming a classroom from an analogue to a digital environment implies new possibilities related to classroom work, but the traditions of how work is conducted in school are strong and remain the superior structuring resource in this case (cf. Edwards \& Mercer, 1987; Selwyn, 1999). The example above shows that the students adjust their actions in accordance with traditional schooling activities conducted using paper and pen. The several options related to cloud sharing of documentation (on Google Drive, Dropbox, etc.) are not utilized; instead, the group chose to send around one iPad and then e-mail the document. As stated earlier, implementation is a slow process (cf. Cuban, 2001; Orlikowski, 2007) and dealing with digital technology mainly as if it were analogue can be considered as an initial step in this process.

Another group of three boys in the Chemistry class organised the group discussion rather easily, as shown in the ethnographic description below:

\section{Ethnographic description 2, Group B}

Joseph takes the lead and Adam is taking notes on the iPad. Jonathan has no particular involvement initially. Joseph has the questions on his screen and they discuss one question at a time. Just like group A, they agree that they will email their text to their teacher and to the rest of the group. When they have gone through the questions, Joseph takes the iPad with the notes and reads through it. He corrects a few spelling mistakes and adds bullets to the answers and checks the changes with Adam and discusses the meaning of certain words in the text.

In Ethnographic description 2, both the group discussion and the technology become structuring resources for the comprehension and processing of the text. The technology enables the students to go back and edit the text once they are finished, and through their negotiation and composing of meaningful written productions, they participate in the meaning of text. However, as the earlier stated example from the same lesson, the periodic table represents a subject-specific text, which is shaped by different cultural functions. Specific cultural functions also shape how the students construct their own text, and negotiations around this aspect are evident in the following excerpt.

$$
\begin{aligned}
& \text { Excerpt 3, Group B } \\
& \text { 1. Joseph: Should we add a picture to the text? } \\
& \text { 2. Adam: Well (.) Then it looks as if we've been on the Internet. } \\
& \text { 3. Joseph: That's true. We'll skip it. }
\end{aligned}
$$

The students mutually reject the use of pictures by agreeing that it would appear as if they have been on the Internet. This could be understood as an alignment to the generic expectations of teachers, which is about producing their texts without copying from the Internet, even though there are no instances in the empirical material where the teacher has explicitly stated this in her introduction. Analytically, it is an example of students participating in the meaning of text, where their interpretation of the particular culture of school as a place where using pictures from the Internet would not be appropriate becomes a structuring resource; however, by that they also use the text more pragmatically or functionally to solve the task in what they believe to be the expected manner.

After this, the class reorganizes into a whole-class activity where the teacher presents the app 'Periodic table of elements', which is summarized with the support of the videorecordings in the ethnographic description below: 


\section{Ethnographic description 4}

The teacher displays the app on the periodic table of elements on a big screen. She carefully instructs how to read the app and encourages the class to search for more similar apps as a support for the upcoming laboratory work. The students take some time to search for apps and meanwhile they discuss and share what they find with one another. They do this by calling out loud, for example 'Look, I found a cool thing'.

Here, the teacher's scaffolding serves as a structuring resource for the students to break the code of the text. By instructing the students in how to read and use the specific app and its features, they get tools for how to read similar apps when doing this work independently. In their discovering of other similar apps, the culture of sharing, which is common in relation to digital technologies becomes another structuring resource (cf. Beetham \& Sharpe, 2013).

During the following part of the lesson, the students are supposed to do a laboratory study to measure the $\mathrm{pH}$ of different liquids and write a lab report, as displayed in ethnographic description 5:

\section{Ethnographic description 5}

The teacher instructs the students that the report is to be done in the iPad app 'Numbers' and documented by using the iPad camera. She does not give any further instruction of how to create a lab report at this point, but focuses on how to make a table in Numbers. The students are instead recommended to find information on these things in the traditional Chemistry book or the Internet. Only a couple of students use the traditional book. No specific instructions are provided for the reading, or how to do a lab report. When they are uncertain, the students not only turn to the Internet but also to each other or to the teacher for support.

At this point, the classroom activity embraces the choices of using both traditional and digital texts, which implies that the majority of the students lean on the information-seeking possibilities offered by the Internet. Thus, they use texts functionally since they are familiar with searching information online. As stated previously, the comprehension of texts may be supported by the use of strategies (e.g. Kress, 2003; Rasmusson \& Eklund, 2013). Reading traditional text is partially different from reading online texts. Therefore, finding and supporting appropriate comprehension strategies for different texts becomes important in teaching. Since, at this point, the teacher does not provide the students with specific instructions either for the reading nor how to do a lab report, they utilize technology as the main scaffolding resource for supporting the reading practices as well as the digital productions in the classroom. In this manner, they find their way towards the goal - to perform a laboratory study and write a lab report — despite the lack of instructions or clear strategies for their reading.

Analytically, several examples of reading practices are visible in the course of this lesson. Different structuring resources can also be identified in order to see how the reading and comprehension is supported. The students are provided with the questions on FB a couple of days in advance and once the organisation of the groupwork is settled, these questions support their comprehension and enable them to get started with the activity more quickly. This setup is in line with earlier research, thereby implying that previous knowledge is important for reading comprehension (cf. Coiro, 2011; Dole et al., 1991; Pearson \& Gallagher, 1983) and supports students in their codebreaking (Freebody \& Luke, 1990). The teacher's instruction regarding the app from the big screen also becomes a structuring resource in the reading practice of breaking the code of texts. This is carried through carefully, and the teacher models and provides the students with strategies for how to find, read, and use other apps within the same area before the students try it on their own. On the other hand, the instructions for the laboratory study and the report itself are more open. Since the teacher only suggests the Chemistry book or the Internet, the lack of more precise support appears to pave the way for students' co-operation, whereby the culture of sharing and 
helping each other to ascertain how best to perform the task becomes a structuring resource in supporting them to use the text functionally.

\section{History}

The content of this particular lesson is to answer questions about Greek philosophers in a printed pamphlet. Here, answering questions is intended to scaffold reading comprehension. The lesson begins with a read aloud from the traditional History schoolbook.

Ethnographic description 6

This lesson's overall aim is to search for information to be able to answer questions, and is begun by reading aloud from the History schoolbook. This initial activity is orchestrated by the teacher, who continuously comments and makes clarifications regarding the text. The subsequent task of answering questions in the pamphlet is an individual task, but the students are encouraged to help each other. Two encyclopaedias on the Internet are recommended as resources, which are web pages organized to facilitate web searching. One is provided by the Swedish National School Agency and the other one is a reputed online encyclopaedia provided by the school through an annual licence. The students are also recommended to use the physical encyclopaedias on the classroom shelves. However, the teacher specifically advises that Google must be avoided. The students use different sources for this purpose without avoiding Google and move between the mandatory paper pamphlets and use of different online resources to find the answers. Apart from the recommendation of using encyclopaedias, the teacher does not provide any particular instruction or support for how to proceed with the task, and the students are given the choice of how to present their answers and which tool they prefer to use.

Analytically, the first part of the lesson is categorized as a reading practice where participating in the meanings of texts as well as how to use texts functionally are central aspects. The teacher's modelling is scaffolding the students' comprehension and supports the creation of meanings of the text by verifying understanding and determining relevance and also how to use the subjectspecific text functionally (cf., Dole et al., 1991). On the other hand, when it comes to the second part of the lesson where the students are to search for information, the teacher's instructions limit them to sources from either physical books or recommended online encyclopaedias. However, most students have formed habits due to their out-of-school experiences with regard to finding information; consequently, to search using Google becomes a structuring resource for in-school activities as well. Therefore, the students reject the teacher's advice and the application intended to be a structuring resource for them. When asking the students regarding their perceptions of available applications, they are rather firm about rejecting the books on the shelves, claiming that it is uncertain whether they contain updated and reliable information (cf., Grimes \& Warschauer, 2008; Gärdén, 2014; Oliver \& Corn, 2008). Even if using various sources for searching information is not new, new challenges evolve in a digital environment. Online encyclopaedias are created to facilitate the searching activity and online reading for the students. Nevertheless, these applications have a design that also needs to be understood in order to be used effectively. They not only contain elements of traditional text but also online reading features, like adopting a critical stance to the text. Comprehension strategies are considered crucial irrespective of whether the reading takes place on paper or in a digital environment (cf., Chan \& Unsworth, 2011; Dalton \& Smith, 2012); in this regard, the students here are left without support.

The teacher's restriction to not use Google was intended to scaffold the students learning since she claims that the sources might be of a varying quality. Since she is also an early learner when it comes to teaching in a technology-rich environment, using optional sources brings in uncertainty in her teaching and becomes a contribution to why she recommends that they use physical encyclopaedias. This confirms the results of research that study the importance of professional development when implementing digital technologies (Fleischer, 2012; Tallvid et al., 2015). Even if 
she intends to scaffold the students by limiting their options online, the students' out-of-school habitual search competence becomes a main structuring resource for them to complete the task and they become pragmatic text users, using the text functionally.

\section{Swedish}

The Swedish lesson comprises of reading individual books, either in traditional formats or from the iPads. The purpose is also to reflect on the reading in a common class blog to support individual and shared reading comprehension. The reading lesson is one in a range of lessons of the same structure. Thirteen students read traditional books, while seven downloaded books on their iPads. The iPad reading implied parts of online searching for books on the library web page. However, all the texts are traditional and presented through different interfaces. This activity also involves reading blog comments from the previous lesson. The blog activity is introduced by the teacher with a step-by-step reading instruction of how to get into the blog and how to find the right target week in a list. The excerpt below is from a sequence of the teachers' instruction regarding the blog with the web page displayed on the big screen.

\section{Excerpt 7}

Teacher: Before beginning your writing today, I want us to have a look at last week's question. Last week's question was whether the things happening in your book actually could happen in real. Motivate your answer and describe why, why, why. The Swedish teacher's favourite. ((smiles)). Question words. Have a quick look at (.) and start by going into the blog

((points at the blog address written on the white board $)$ ).

Find week eleven and go in there and read what your classmates have written and how they have taken on this question.

((The teacher waits for a short while when the students find the right part in the blog and begin reading))

Teacher: When you have finished reading, I want you to answer this week's question.

There are almost no questions at all in the room and the movement between the reading of the book and the use of the blog is habitual and thereby works smoothly. The careful instruction initiating this activity works in a similar manner as the teacher's introduction of finding apps in the Chemistry class. In this case, the careful instructions made by the teacher scaffolds the students by eliminating doubts in their progress of browsing on the web and reading and writing in the blog. Thus, the teacher's hands on, step-by-step instruction becomes an important structuring resource for the students to break the code of texts and tackle the tasks.

When the students have read their classmates' posts from last week, they are supposed to post new comments regarding their reading derived from a question posed by the teacher: What genre would you consider your book to represent and why? After a short instruction around genres and examples, the students begin writing. When they are finished, the teacher continues:

\section{Excerpt 8}

Teacher: The reason why I wanted you to read last week's answers is that I think you seem to have (.) got a bit going. Many of you have begun thinking and reflecting and also begun writing more and longer answers. And as I have a quick look at your reflections on this week's question,

((looks at the blog page on her iPad screen while talking to the class))

I see that it's getting longer and longer. You can reply to things I didn't really ask for but still connect it to your answers (.), for example, relating something that has 
to do with the answer, describing, and giving examples from the book. You show that you think. Of course I know you think a lot but now you're also showing me that, which is really, really good. We'll keep doing it like that. It's also rather fun to read what other people write. You could get some tips and ideas of how you could think and also get some examples of how you can continue your own reflection.

The above excerpt shows how the teacher explicitly explains why the reflection in the blog is constructive for the students' emerging reading literacy competence. First, she praises their writing progress and also describes the manner in which their writing has become better, which also implies a deepened reading comprehension. She mentions that the texts are getting longer but also that the children are appearing to write their reflections more independently by widening their perspective. She also emphasizes that the shared space of the blog can support their ongoing writing.

The iPad is present during the reading and reflection parts - as an option, when it comes to the reading, but mandatory through the blogging. By utilizing the blog for writing, the writing becomes intertwined with the classmates' ideas and formulations, which becomes a structuring resource in the students' literacy development. This becomes visible in the teachers' presentation of how their blog posts, as public texts, have become not only longer, but also more relevant, elucidatory, and connective (e.g. Applebee \& Langer, 2011). The sharing also enhances and contributes to the students' participation in the meanings of texts.

\section{English}

The content of the English lesson is online reading comprehension. The class is supposed to use a web page (http://www.efl247.com), which is a resource for learners of English as a foreign language, containing up to date newspaper articles (often with links from Children's BBC) and other assets to aid comprehension.

\section{Ethnographic description 9}

The teacher introduces the activity step by step with her iPad projected on the screen. She guides them through registration, logging in, and she also presents the structure of the web page and how they can search and find the article for the day. The English-English wordlist within the site is also presented and she shows them how to use it by an explicit example. She introduces the task, which is to read the text and answer the questions in a 'true and false' section as a way to confirm reading comprehension

Through the entire instruction, the teacher is attentive to whether the students are following her instructions, and during her instruction she also moves around the room to help. The instructions for this activity are mostly at a navigating-level, for example, how to switch between pages during the activity and how to use the wordlist as a resource. The different instructions around how to deal with and use the features of the text as well as understand the pattern is a way of scaffolding and becomes a structuring resource in the students work with breaking the code of texts.

After finishing reading, they do a read-aloud activity; by doing this, they go through the text in a more traditional manner. The students read one at a time and the teacher scaffolds the comprehension by commenting now and then on the content in order to support the students' participation in the meanings of the text. Then, the teacher proposes that the students create their own word list. Utterances that originally are made in English are here marked with bold letters.

Excerpt 10:

\section{Teacher: So did you find this text easy to read or a bit tricky? \\ 2. Adam: Tricky}


3. Teacher: A bit tricky? ((other students say 'easy')). Easy? There are some words I believe that you found difficult to understand. Could you please help me out (.) to make it a wordlist? Emma?

4. Emma: Gutter

5. Teacher: Gutter? Good. More?

((No answer from the class))

6. Teacher: Was this the only tricky word in this text? So if I give you a test on Friday, that won't be a problem? No?

7. Joseph: What is 'estimated'?

8. Teacher: Good! What's estimated?

9. Jennifer: What you believe?

10. Teacher: Okay, what you believe or estimate. Good.

11. Adam: Is 'gutter' where water is raining from the roof? ((The student has checked the word in a wordlist app on the iPad and obtained this as one of the translations))

12. Teacher: Rain gutter? No it's not but it's a kind of similar thing where water is going along the street, for example, beside the sidewalk. A gutter.

With an intention to provide scaffolding for the students' comprehension, the teacher suggests making a word list of difficult words. However, there is already a word list to be found in the text and the students have translation apps open on their iPads in front of them. Analytically, this excerpt serves as an example of practices that are still very much attached to traditional schooling. Traditionally, language teachers have used wordlists and close work on vocabulary as a way of supporting comprehension. However, in a digital classroom where most students also have access to their smart phones and instant translation apps, making this kind of word list could be regarded as redundant if it is not used to discuss different interpretations, as is initiated in Adam's question in turn 11. Then, the entire task may serve as an example of situations appearing in a classroom in the transition from an analogue to a digital classroom, where the potential of technology is not fully utilized. Thus, the literacy event that could have involved several of the four multiliterate functions is focusing on a rather shallow code breaking activity.

The comprehension activity continues by an initiative from the teacher regarding how much a pound is, which is displayed in the excerpt below.

Excerpt 11:

1. Teacher: How do we know exactly how much is a pound? Well (.) you could download the Forex app. It's a great application to have if you're planning to go abroad. To see what currency they have and what it's worth.

2. Adam: GBP?

3. Teacher: Yes, GBP. What does it stand for?

4. Anna: Great Britain Pound

5. Teacher: Yes

6. Lucas: But there are two different ones. One 'selling' and one 'buying'.

7. Teacher: Mmm. And are we selling or buying if we're going?

8. Lucas: Buying?

9. Teacher: We are buying pounds 
10. Sophie: It is 10 comma 31 ?

11. Teacher: Pardon? ((The student repeats)) Well, about 10 point 31 today. It may be something else tomorrow. We don't know that.

(pause)

12. Teacher: So how much is those (.) 12 million then? John!

13. Joseph: One hundred and twenty-three million kronor and twenty thousand.

14. Teacher: Thank you very much. Very exact.

In a digital classroom, information is always accessible and accessing different information is possible at all times. Here, it is all about making clarifications about parts of the text in order to comprehend it. Therefore, strategies for finding information, which implies participating in the meaning of text, would be considered crucial for reading comprehension. The specific use of the technology for information searching becomes a structuring resource in the students'work, but it is the teacher's scaffolding of the reading that becomes most important. She models how to take on the text when running into comprehension problems. She is doing this by the opening up the question on how much a pound is, and how to find out exactly (turn 1). As a resource, she recommends to the students to download the Forex currency app and states that it is good to have when travelling. By doing that, she supports a literacy event involving the students in how they can utilize this in an out-of-school context. Analytically, this shows an example of a reading practice that mainly is about participating in the meanings of text, but since the reading of the currency app is a specific text that requires specific comprehension strategies, the teacher is also scaffolding how to use this specific text functionally. Compared to the read-aloud activity and the word list activity, there is an active engagement in the entire group. Thus, even if the teacher takes the initiative of highlighting the issue of a pound, the question seems to engage the students. This confirms what earlier studies state - that the opportunities of encountering occasions for learning on the spot increase in a 1:1 environment (Grimes \& Warschauer, 2008).

\section{Mathematics}

The purpose of the mathematics lesson is to work in pairs and search, find, and use statistics from the Swedish statistics webpage (SCB). Questions for the activity were e-mailed to the student in advance. In the empirical material, two groups are in focus, and in both groups one student is writing down the answers on the iPad while the other student has the SCB open on his screen. Negotiations regarding difficult words from the webpage are taking place continuously throughout the task, which also involves raising questions aloud in the room in order to find support from others. This is displayed in the following excerpt:

Excerpt 12:

1. Adrian: Hey Anne (teacher), the words are far too difficult on this page

((Teacher is busy helping another student so she isn't responding))

2. Lucas: What is centralisation? ((asked aloud to the class))

Occasionally, it is the teacher that helps by answering and at other times it is another student. In a more general sense, the students do not seem to realize that they have the sources right in front of them. By using different search engines on their iPads they could easily have found the answers. However, the frequent questions posed aloud are revealed as a popular structuring resource for them. Gradually, after browsing the web page, the students seem to sort out the structure and how to use the text functionally. In this, they find FAQ (Frequently Asked Questions) and the questions asked aloud reduce. 
The lesson is mainly an example of online reading. The representation of the text is partially different from a traditional one, for example, due to the multimodal elements and the hyperlink structure which requires reading practices both on how to break the code of texts, participate in the meanings of text, how to use this specific text functionally, and also how to culturally analyze the text, since it represents the particular views of a state agency. However, during this lesson, the teacher takes a step back in terms of supporting the reading of the web page. It is very much up to the students to find their own way here. On one hand, this is not in line with the previously discussed importance of teaching strategies and scaffolding. On the other hand, the great variety of text we encounter on the web can never be completely covered by teaching. Here, the questions that are e-mailed in advance are intended to scaffold the upcoming reading activity, but once in the classroom, the students' collaboration in helping one another also becomes the main structuring resource.

\section{Summary of the Empirical Findings}

The findings from the study of five different subjects in a week of schooling illustrates that three out of the four reading practices emanating from the Four Resources Model (Freebody \& Luke, $1990,1999,2003)$ take place supported by a variation of structuring resources, as displayed in Table 2.

The particular significant approaches, in the activities as well as in the scaffolding provided by the teacher, are using the texts functionally and participation in the meanings of text. These two approaches are recurrently supported by the students' previous knowledge of handling the technology and support from their peers. Elements of breaking the code of texts are often combined with the teacher's step-by-step instructions or a fundamental use of technological applications such as translation apps in the English classroom. The fourth category involving critically analyzing and transforming texts is not explicitly present in the empirical material.

In certain cases, the literacy events become apparent examples of a classroom in transition from analogue to digital, where some choices are based on traditions that still may be useful but seem less relevant for the students, for example, finding information in traditional encyclopaedias in the History class, finding information on lab reports in traditional Chemistry books, taking notes on the iPad and sending it around the group or create word lists for comprehension in English. It is not surprising that the traditions of task-solving activities where the texts are used functionally or how to break the code of texts are supported by the teacher. However, the students' previous out-of-school knowledge of handling the technology implies that they recurrently create their own path, occasionally neglecting the teacher's instructions. Therefore, not only the teacher's scaffolding but also their peers' support in, for example, sharing findings and advice become structuring resources in the literacy events.

Comprehending the specific, encountered text and turning it into meaning is central in the use of text in educational environments. Therefore, bringing the content of the text closer to the reader and making connections to previous knowledge possible by participating in the meanings is also part of the main support from teachers.

Breaking the code of text becomes central when the teachers are modelling and scaffolding in read-aloud activities or how to read and navigate a web page or an app. Then, the focus is to identify and recognize patterns and conventions both in traditional text on paper and online texts.

Despite an educational setting with constant and instant access to digital technologies and the Internet, very little time is spent on activities and structuring resources that support the students in how to critically analyze and transform texts. With the constant access to all the information in the world, such skills become increasingly important. Thus, the understanding that texts represent particular views but also silence others, as well as how they influence people's ideas are crucial. 
Moreover, knowledge of how text designs and discourses can be critiqued and redesigned in new and hybrid ways also becomes important. The choice among the boys in the Chemistry class to avoid using pictures from the Internet in their presentation may be one example of the insecurity that may arise around these issues.

Table 2: Overview of the findings

\begin{tabular}{|c|c|c|c|}
\hline $\begin{array}{l}\text { Excerpt/ } \\
\text { Ethnographic } \\
\text { description }\end{array}$ & Subject & Significant reading practices & Significant structuring resources \\
\hline Excerpt 1 & Chemistry & Using the text functionally & $\begin{array}{l}\text { The traditional task-solving practice of } \\
\text { schooling }\end{array}$ \\
\hline $\begin{array}{l}\text { Ethnographic } \\
\text { description } 2\end{array}$ & Chemistry & Participating in the meanings of text & $\begin{array}{l}\text { Both the group discussion and use of } \\
\text { technology }\end{array}$ \\
\hline Excerpt 3 & Chemistry & $\begin{array}{l}\text { Participating in the meaning of text } \\
\text { intertwined with using the text } \\
\text { functionally }\end{array}$ & $\begin{array}{l}\text { Their interpretation of the particular } \\
\text { culture and task-solving practise of } \\
\text { schooling }\end{array}$ \\
\hline $\begin{array}{l}\text { Ethnographic } \\
\text { description } 4\end{array}$ & Chemistry & Breaking the code of the text & $\begin{array}{l}\text { The teacher's scaffolding and the cul- } \\
\text { ture of sharing }\end{array}$ \\
\hline $\begin{array}{l}\text { Ethnographic } \\
\text { description } 5\end{array}$ & Chemistry & Using the text functionally & $\begin{array}{l}\text { The technology is the main scaffolding } \\
\text { resource along with peers and the } \\
\text { teacher }\end{array}$ \\
\hline $\begin{array}{l}\text { Ethnographic } \\
\text { description } 6\end{array}$ & History & $\begin{array}{l}\text { Participating in the meaning of text } \\
\text { Using the text functionally }\end{array}$ & $\begin{array}{l}\text { The teacher's modelling in the read- } \\
\text { aloud part scaffolds the students' com- } \\
\text { prehension } \\
\text { The technology and the students' out- } \\
\text { of-school search competence }\end{array}$ \\
\hline Excerpt 7 & Swedish & Breaking the code of the text & $\begin{array}{l}\text { The teacher's hands-on, step-by-step } \\
\text { instruction }\end{array}$ \\
\hline Excerpt 8 & Swedish & Participating in the meaning of text & $\begin{array}{l}\text { The technology and the possibility of } \\
\text { making texts public }\end{array}$ \\
\hline $\begin{array}{l}\text { Ethnographic } \\
\text { description } 9\end{array}$ & English & Breaking the code of the text & $\begin{array}{l}\text { The teachers' step-by-step instruction } \\
\text { on how to use the features of the digi- } \\
\text { tal text }\end{array}$ \\
\hline Excerpt 10 & English & Breaking the code of the text & $\begin{array}{l}\text { The use of the translation app technol- } \\
\text { ogy (translation apps) and the teach- } \\
\text { ers' dialogue }\end{array}$ \\
\hline Excerpt 11 & English & $\begin{array}{l}\text { Participating in the meaning of text } \\
\text { and using the text functionally }\end{array}$ & $\begin{array}{l}\text { The use of technology for information } \\
\text { searching; however, the teacher's } \\
\text { scaffolding becomes most important. }\end{array}$ \\
\hline Excerpt 12 & Mathematics & Using the text functionally & $\begin{array}{l}\text { Peer-support by asking questions } \\
\text { aloud. }\end{array}$ \\
\hline
\end{tabular}




\section{Discussion}

This study focused on the structuring resources and reading practices utilized for students' work related to digital technology and teacher instructions in five literacy events in an ordinary school week. The research questions comprised what reading practices that were significant, which aspects that turned out to be structuring resources in the activities and the implications in terms of evoking reading practices. The findings imply that there is a strong focus on task-solving, where the practice of schooling, to a great extent, still builds on the principles emanating from traditional text; it is only occasionally that elements that include the opportunities that digital technology offers are emphasized. In such instances where the technologies are used more inclusively, the possibilities of using the technology and help from peers become the main structuring resources. The teacher mostly contributes with scaffolding of the reading practice that recognizes features of text conventions and patterns of traditional reading on the web pages or apps, in line with the approach of breaking the code of texts. In relation to this finding it is, however important to bear in mind that the basis of traditional reading comprehension is by no means unimportant in a digital context; rather, the support in three out of four approaches (Freebody \& Luke, 1990, 1999, 2003) provided by the teachers in our study is fundamental to developing reading literacy in a digital environment (cf., Chan \& Unsworth, 2011; Dalton \& Smith, 2012).

For centuries, a key function of the educational system has been to provide students with basic reading skills. However, due to the rapid evolving technologies and their impact on the representation of text and, thereby, what it is to read, the premises for schoolwork and instruction related to reading literacy are changing. The findings of our study aligned with findings from many earlier studies, and policy reports suggest that skills for dealing with the traditional, typographical text are no longer sufficient alone. Today, the reader needs a combination of approaches to meet the requirements of both typographical reading and online reading (e.g. Ackerman \& Goldsmith, 2011; Baker, 2010; Chan \& Unsworth, 2011; Dalton \& Smith, 2012; Kim \& Huynh, 2010; Kress, 2003; OECD, 2015; Öman \& Svensson, 2015; Rasmusson \& Eklund, 2013). In line with the Four Resources Model (Freebody \& Luke, 1990, 1999, 2003), the reader needs to be able to break the code of multiple texts, where multimodal components are as present as traditional text. Further, the reader also needs to be able to participate in meanings of text by adapting the reading to different cultures, institutions, communities, etc. Strategies for comprehension become diverse with multiple texts in new contexts. Texts are also differently constructed with different tones and degrees of formality, depending on the cultural and social functions they exist in. Therefore, the amount of text that readers are exposed to today requires good knowledge from the reader in terms of how to use a text functionally. Furthermore, in a multimodal world, with an endless number of occasions where online information and knowledge is encountered, the skills of critically analyzing and transforming texts becomes particularly crucial. Knowledge of how texts represent particular views but also silence others is important in selecting and critically dealing with texts.

Web 2.0 and its interactivity also provide possibilities for redesigning texts and discourses in ways that were not possible a decade ago. However, these approaches are not easily separable in literacy events; in this study, they are used merely as analytical lenses to scrutinize which approaches become significant in the reading practices of 1:1 schooling. This corresponds with the basis of the approaches put forward by Freebody and Luke (1990, 1999, 2003), assuming that

'...each of these general families of approaches displays and emphasises particular forms of literacy, such that no single one will, of itself, fully enable students to use texts effectively, in their own individual and collective interests, across a range of discourses, texts and tasks' (Freebody \& Luke, 1990, p. 7-8). 
Thus, all four approaches need to be part of the learning opportunities in transitions from analogue to digital literacy practices in schooling. To orchestrate this, scaffolding structures need to be developed to support students' knowledge in managing and producing various texts that move beyond pragmatic text-productions in task-solving activities (cf., Rasmussen \& Eklund, 2013). To enable such development, educators need to receive sufficient in-service training to keep up to date with new literacies that appear online. These conclusions coincide with previous research findings, which indicate that in-service training for teachers is essential for successful implementation of digital technologies. Otherwise, there is a risk that the instructions and classroom practices continue to focus on analogue text productions, where the technologies become merely an add-on to the existing practice, and the possibilities that they entail are not utilized (Andersson et al., 2014; Cuban, 2013; Öman \& Svensson, 2015). Another, perhaps more perilous, risk is that too much emphasis is placed merely on specific approaches of reading literacy related to the use of digital technology in education, thereby neglecting the basic skills that are necessary to be able to use literacy functionally (cf., Selwyn, 2015). An excessive orientation towards hands-on introductions of technological applications, as is partially seen in our study, might reposition the focus from important basic, essential, and subject content. Thus, it is imperative to acknowledge the importance of scaffolding as not only the basis of traditional reading comprehension but also as a tool to make space for new approaches that are needed in a digital environment.

\section{Conclusion}

In accordance with earlier studies, the concluding remarks from this study suggest that the reading practices that are significant in a 1:1 educational context predominantly emanate from traditional texts, which confirms that traditions of schooling are strong and that implementing new technologies is a gradual process. Digital technologies are often made use of merely as a substitute for former technologies and the built in possibilities of the tools are not fully exploited. For the reading practices, this suggests that the traditionally strong focus on scaffolding students' experiences of how to break the code of texts remains unprovoked. These aspects become important structuring resources in the students' activities. Since the ways the students make use of the possibilities of the technologies are strongly linked to teacher instructions, the teachers' framing of the lesson is crucial for the application of the technology and the evoking reading practices (cf. Öman \& Svensson, 2015). On the other hand, the findings of this study also imply that the students' out-of-school experiences and interests play important roles in the activities and become structuring resources that sometimes represent contradictions in relation to the instructions. An explicit example of this from our study is in the History lesson when the teacher explicitly instructs the students to avoid using Google and instead recommends them to use the encyclopedia books. Here the students' previous experiences and habits of searching for information take precedence. In rejecting the books, the students ground this stance in arguing that the books are not so easily updated and by that the students show signs of critical competence that in the overall empirical material is rare. We argue, that in order to move 1:1 classroom activities beyond practices that merely emanate from traditional text, an important step would be to embrace the students' experiences and initiatives since they commonly have acquired certain kinds of literacy skills that should be accounted for in the continued development of reading literacy.

There are of course limitations to the present study, which is not unusual in qualitative studies (cf., Yin, 2012). Our study covers only one week in a technology-rich classroom and the number of participants was limited to those in one class. However, the study emphasizes the exploration of a phenomenon within the natural setting of ongoing schooling, which makes it possible to learn about real-world behaviour with implications for research and practitioners alike. Since reading practices in classrooms are central for learning, the difficulties of changing traditional habits when using digital devices have many aspects in common across subjects. Therefore, future studies that focus on how to support reading practices in different subjects are needed. 


\section{References}

Ackerman, R. \& Goldsmith, M. (2011). Metacognitive regulation of text learning: On screen versus paper. Journal of Experimental Psychology: Applied, 17(1), 18-32.

Andersson, A., Hatakka, M., Grönlund, Å., \& Wiklund, M. (2014). Reclaiming the students-Coping with social media in 1:1 schools. Learning, Media and Technology, 39(1), 37-52.

Applebee, A. N., \& Langer, J. A. (2011). A snapshot of writing instruction in middle schools and high schools. English Journal, 100(6), 14-27.

Baker, R. D. (2010). Comparing the readability of text displays on paper, e-book readers, and small screen devices (Doctoral dissertation). University of North Texas, Ann Arbor: ProQuest.

Beetham, H., \& Sharpe, R. (2013). An introduction to rethinking pedagogy. In H. Beetham \& R. Sharpe (Eds.), Rethinking pedagogy for a digital age: Designing for 21 st century learning (2nd ed.), (pp. 110). New York: Routledge.

Buckingham, D. (2003) Media education: Literacy, learning and contemporary culture. Cambridge: Polity Press.

Buckingham, D. (2013). Beyond technology: Children's learning in the age of digital culture. Malden, MA, USA, Polity Press

Chan, E., \& Unsworth, L. (2011). Image-language interaction in online reading environments: Challenges for students' reading comprehension. The Australian Educational Researcher, 38(2), 181-202.

Codex. (2010). Rules and guidelines for research. Retrieved May, 2015 from http://codex.vr.se/manniska2.shtml

Coiro, J. (2011). The Online Reading Comprehension Assessment (ORCA) Project: Preparing Students For Common Core Standards and 21 st Century Literacies.

Collins, A., \& Halverson, R. (2009). Rethinking education in the age of technology: The digital revolution and schooling in America. New York: Teachers College Press.

Cuban, L. (2001). Oversold and underused —Computers in the classroom. Cambridge, MA: Harvard University Press.

Cuban, L. (2013). Inside the black box of classroom practice: Change without reform in American education. Cambridge, MA: Harvard Education Press.

Dalton, B., \& Smith, B. E. (2012). Teachers as designers: Multimodal immersion and strategic reading on the Internet. Research in the Schools, 19(1), 12-25.

Davidson, R. G., Kline, S. B., \& Snow, C. E. (1986). Definitions and definite noun phrases: Indicators of children's decontextualized language skills. Journal of Research in Childhood Education, 1, 37-48.

Dole J. A., Duffy, G. G., Roehler, L. R., \& Pearson, P. D. (1991). Moving from the old to the new: Research on reading comprehension instruction. Review of Educational Research, 61(2), 239-264.

Donovan, L., Hartley, K., \& Strudler, N. (2007). Teacher concerns during initial implementation of a oneto-one laptop initiative at the middle school level. Journal of Research on Technology in Education, 39(3), 263-286.

Duranti, A. (1997). Linguistic anthropology. New York: Cambridge University Press.

Edwards, D., \& Mercer, N. (1987). Common knowledge: The development of joint understanding in the classroom. London: Methuen.

Erstad, O. (2006). A new direction? Digital literacy, student participation and curriculum reform in Norway. Education and Information Technologies, 11(3/4), 415- 429.

Ertmer, P. A., Ottenbreit-Leftwich, A. T., Sadik, 0., Sendurur, E., \& Sendurur, P. (2012). Teacher beliefs and technology integration practices: A critical relationship. Computers \& Education, 59(2), 423-435. 
European Commission. (2011). CIP 2011 implementation report. Luxemburg: European Commission

Findahl, O. (2012). Swedes and the Internet 2011. Stockholm: SE

Fleischer, H. (2012). What is our current understanding of one-to-one computer projects: A systematic narrative research review. Educational Research Review, 7(2), 107-122.

Freebody, P., \& Luke, A. (1990). Literacies programs: Debates and demands in cultural context. Prospect: An Australian Journal of TESOL, 5(3), 7-16.

Freebody, P., \& Luke, A. (1999). Further notes on the Four Resources Model. Reading Online. Retrieved from http:www.readingonline.org/research/lukefreebody.html

Freebody, P., \& Luke, A. (2003). Literacy as engaging with new forms of life: The "four roles" model. In G. Bull \& M. Anstey (Eds.), The literacy lexicon (2nd ed.) (pp. 51-66). Frenchs orest, NSW: Pearson Education.

Gee, J. P. (1991). Social linguistics: Ideology in discourses. London: Falmer Press.

Goodwin, B. (2011). One-to-one laptop programs are no silver bullet. Educational Leadership, 68(5), 7879.

Grimes, D., \& Warschauer, M. (2008). Learning with laptops: A multi-method case study. Journal of Educational Computing Research, 38(3), 305-332.

Guthrie, J. T., Klauda, S. L., \& Ho, A. N (2013). Modeling the relationships among reading instruction, motivation, engagement, and achievement for adolescents. Reading Research Quarterly, 48(1), 9-26.

Gärdén, C. (2014). Vuxenstuderande och informationskompetens. (Adult learners, and information literacy). In J, Rivano Eckerdal \& O. Sundin (Eds.), Medie- och informationkunnighet - en forskningsantologi. (Media and Information Literacy - a research anthology) pp. 63-75. Svensk biblioteksförening. (Swedish Library Association).

Hymes, D. (1967). Models of the interaction of language and social setting. Journal of Social Issues, 23(2), 8-38.

Hymes, D. (1972). On communicative competence. In J. B. Pride \& J. Holmes (Eds.), Sociolinguistics: Selected Readings (pp. 269-293). Harmondsworth: Penguin.

Inan, F. A., \& Lowther, D. L. (2010). Factors affecting technology integration in K-12 classrooms: A path model. Educational Technology Research and Development, 58(2), 137-154.

Jefferson, G. (1984). Transcription notation. In J. Atkinson \& J. Heritage (Eds.), Structures of social interaction. New York: Cambridge University Press.

Jones, R. (2014). Digital literacies for language teachers: Beyond competencies. A plenary addressed at the 61st TEFLIN international conference, Solo, Indonesia.

Jordan, B., \& Henderson, A. (1995). Interaction analysis: Foundations and practice. The Journal of the Learning Sciences, 4(1), 39-103.

Kalantzis, M., Cope, B. \& Harvey, A. (2010). Assessing multiliteracies and new basics. Assessment in Education: Principles, Policy \& Practice, 10(1), 15-26.

Kim, D. \& Huynh, H. (2010). Equivalence of paper and pencil and online administration modes of the statewide English test for students with and without disabilities. Educational Assessment, 15(2), 107 121.

Kress, G. (2003). Literacy in the new media age. New York: Routledge.

Lave, J. (1988). Cognition in practice: Mind, mathematics, and culture in everyday life. New York, NY: Cambridge University Press.

Lave, J., \& Wenger, E. (1991). Situated learning: Legitimate peripheral participation. Cambridge: Cambridge University Press. 
Leu, D. J., Kinzer, C. K., Coiro, J. L., \& Cammack, D. W. (2004). Toward a theory of new literacies emerging from the Internet and other information and communication technologies. Theoretical Models and Processes of Reading, 5(1), 1570-1613.

Leu, D. J., Kinzer, C. K., Coiro, J., Castek, J., \& Henry, L. A. (2013). New literacies: A dual-level theory of the changing nature of literacy, instruction, and assessment. In D. E. Alvermann, N. J. Unrau, \& R. B. Ruddell (Eds.), Theoretical models and processes of reading (6th ed.). Newark, DE: International Reading Association. doi:10.1598/0710.42

Levinson, P. (1999). Digital McLuhan: A guide to the information millennium. London: Routledge.

Mangen, A.,Walgermo, B. R., \& Brönnick, K. (2013). Reading linear texts on paper versus computer screen: Effects on reading comprehension. International Journal of Educaional Research, 58, 61-68.

McLuhan, M., \& Lapham, L. H. (1994). Understanding media: The extensions of man. The MIT Press: Cambridge. MA.

OECD. (2015). PISA 2015. Draft reading literacy framework. Retrived May 28, 2015 from http://www.oecd.org/pisa/pisaproducts/Draft $\% 20$ PISA $\% 202015 \% 20$ Reading $\% 20$ Framework $\% 20 . p d f$

Oldknow, A., \& Taylor, J. (2003). Teaching mathematics using information and communication technology. London: Continuum.

Oliver, K., \& Corn, J. (2008). Student-reported differences in technology use and skills after the implementation of one-to-one computing. Educational Media International, 45(3), 215-229.

Orlikowski, W. J. (2007). Sociomaterial practices: Exploring technology at work. Organization Studies, 28(9), 1435-1448.

Öman, A., \& Sofkova Hashemi, S. (2015). Design and redesign of a multimodal classroom task - Implications for teaching and learning. Journal of Information Technology Education: Research, 14, 139-159. Retrieved from http://www.informingscience.org/Publications/2127

Öman, A., \& Svensson, L. (2015). Similar products different processes : Exploring the orchestration of digital resources in a primary school project. Computers \& Education, 81, 247-258.

Østerud, S. (2004). Utdanning for informasjonssamfunnet. Den tredje vei. (Education for the information society. The third way.) Universitetsforlaget: Oslo.

Papastergion, M. (2009). Digital game-based learning in high school computer science education: Impact on educational effectiveness and student motivation. Computers and Education, 52(1), 1-12.

Pearson, P. D., \& Gallagher, M. C. (1983). The instruction of reading comprehension. Contemporary Educational Psychology, 8(3), 317-344.

Prior, P., \& Thorne, S. L. (2014). Research paradigms: Beyond product, process, and social activity. In EM, Jakobs \& D. Perrin (Eds.), Handbook of writing and text production: The Mouton de Gruyter handbooks of applied linguistics series vol. 10. Berlin: Mouton deGruyter

Rasmusson, M., \& Eklund, M. (2013). "It's easier to read on the Internet-you just click on what you want to read...": Abilities and skills needed for reading on the Internet. Education and Information Technologies, 18(3), 401-419.

Scribner, S., \& Cole, M. (1981). The psychology of literacy. Cambridge Harvard University Press.

Selwyn, N. (1999). Why the computer is not dominating schools: A failure of policy or a failure of practice? Cambridge Journal of Education, 29(1), 77-91.

Selwyn, N. (2015). Minding our language_Why education and technology is full of bullshit and what might be done about it. Paper presented in the 'Digital Innovation, Creativity \& Knowledge in Education' conference, January 2015, Qatar.

Serafini, F. (2012). Expanding the four resources model: Reading visual and multi-modal texts. Pedagogies: An International Journal, 7(2), 150-164. 
Shapiro, J. J., \& Hughes, S. K. (1996). Information literacy as a liberal art. Educom Review, 31(2), 31-35.

Sipilä, K. (2011). No pain, no gain? Teachers' implementing ICT in instruction. Interactive Technology and Smart Education, 8(1), 39-51.

Skantz Åberg, E., Lantz-Andersson, A., \& Pramling, N. (2015). "I think it should be a little like exciting": A technology-mediated story-making activity in early childhood education. In S. Garvis, \& N. Lemon (Eds.), Understanding digital technologies and young children-an international perspective (pp. 7491). London and New York: Routledge.

Street, B. V. (1984). Literacy in theory and practice (Vol. 9). Cambridge: Cambridge University Press.

Street, B. V. (1998). New literacies in theory and practice: What are the implications for language in education? Linguistics and Education, 10(1), 1-24.

Säljö, R. (2010). Digital tools and challenges to institutional traditions of learning: Technologies, social memory and the performative nature of learning. Journal of Computer Assisted Learning, 26(1), 5364.

Säljö, R. (2012). Literacy, digital literacy and epistemic practices: The co-evolution of hybrid minds and external memory systems. Nordic Journal of Digital Literacy, 1, 5-19.

Tallvid, M., Lundin, J., Svensson, L. \& Lindström, B. (2015). Exploring the relationship between sanctioned and unsanctioned laptop use in a 1:1 classroom. Journal of Educational Technology \& Society, $18(1), 237-249$.

Uschioda, E. (2011). Language learning motivation, self and identity: Current theoretical perspectives. Computer Assisted Language Learning, 24(3), 199-210.

Vygotsky, L. S. (1939/1978). Mind in society: The development of higher psychological processes. Cambridge, MA: Harvard University Press.

Wegerif, N., Mercer, N. \& Dawes, L. (1999). From social interaction to individual reasoning: An empirical investigation of a possible socio-cultural model of cognitive development. Learning and Instruction, $9(6), 493-516$.

Wells, G. (1999). Dialogic inquiry: Towards a sociocultural practice and theory of education. Cambridge: Cambridge University Press.

Wertsch, J. V. (1998). Mind as action. New York, NY: Oxford University Press.

Yang, Y-T.C., \& Wu, W-C. I. (2012). Digital storytelling for enhancing student academic achievement, critical thinking and learning motivation: A year-long experimental study. Computers \& Education, 59(2), 339-352.

Yin, R. K. (2012). Applications of case study research (3rd ed.). Thousand Oaks, CA: SAGE. 


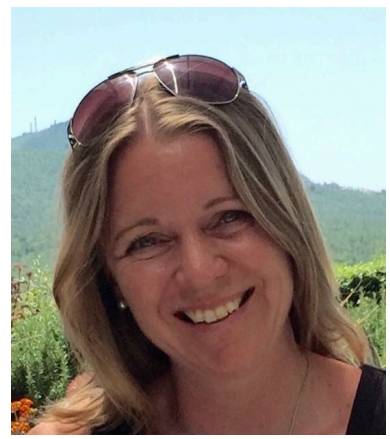

\section{Biographies}

Lisa Molin is a PhD-student at the Department of Applied IT, University of Gothenburg and a member of The Linnaeus Centre for Research on Learning, Interaction and Mediated Communication in Contemporary Society (LinCS). She is also an experienced Secondary school teacher of Swedish and English and works part time as a school development advisor at the Center for School Development in the City of Gothenburg. The focus of Lisa's PhD studies is literacy practices in digital learning environments.

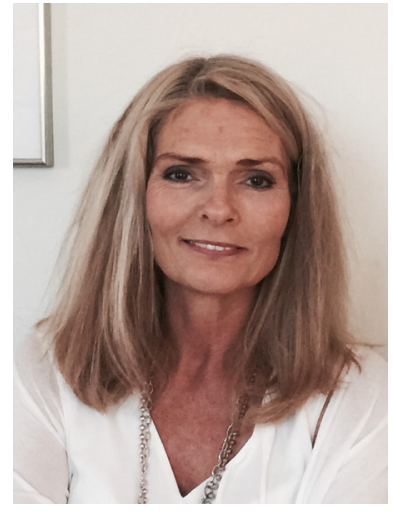

Annika Lantz-Andersson is Associate Professor in Education at the University of Gothenburg and a member of The Linnaeus Centre for Research on Learning, Interaction and Mediated Communication in Contemporary Society (LinCS), as well as part of the University of Gothenburg's strength area of learning research (LETStudio). Annika has a PhD in educational science (2009), and her research focuses on social interaction, the use of digital technologies and its implications for learning. She is currently involved in several research projects concerning young peoples' participation and learning in contemporary media ecologies. 